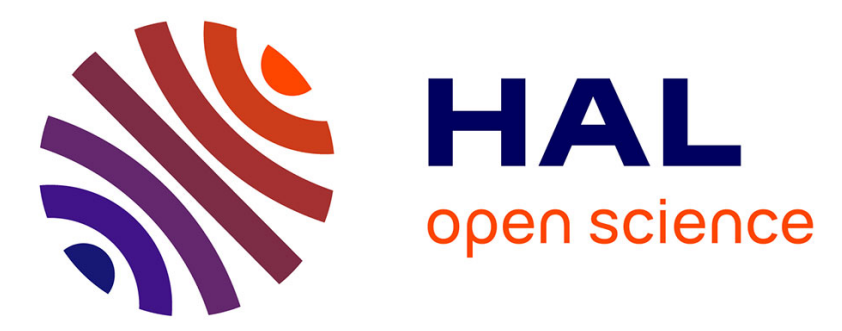

\title{
Sound absorption properties of a sunflower composite made from crushed stem particles and from chitosan bio-binder
}

Narimane Mati-Baouche, Hélène de Baynast, Philippe Michaud, Thomas Dupont, Philippe Leclaire

\section{To cite this version:}

Narimane Mati-Baouche, Hélène de Baynast, Philippe Michaud, Thomas Dupont, Philippe Leclaire. Sound absorption properties of a sunflower composite made from crushed stem particles and from chitosan bio-binder. Applied Acoustics, 2016, 111, pp.179-187. 10.1016/j.apacoust.2016.04.021 . hal01326050

\section{HAL Id: hal-01326050 \\ https://hal.science/hal-01326050}

Submitted on 6 Jun 2016

HAL is a multi-disciplinary open access archive for the deposit and dissemination of scientific research documents, whether they are published or not. The documents may come from teaching and research institutions in France or abroad, or from public or private research centers.
L'archive ouverte pluridisciplinaire HAL, est destinée au dépôt et à la diffusion de documents scientifiques de niveau recherche, publiés ou non, émanant des établissements d'enseignement et de recherche français ou étrangers, des laboratoires publics ou privés. 


\title{
Sound absorption properties of a sunflower composite made from
}

\author{
crushed stem particles and from chitosan bio-binder \\ Narimane Mati-Baouche ${ }^{\mathrm{a}}$, Hélène de Baynast ${ }^{\mathrm{a}}$, Philippe Michaud ${ }^{\mathrm{a}}$, Thomas Dupont ${ }^{\mathrm{b}}$, Philippe Leclaire ${ }^{\mathrm{b}, *}$
}

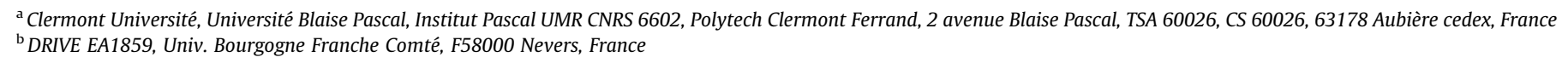

\begin{abstract}
A recent study investigated the mechanical, thermal and acoustical properties of a bio-based composite made from crushed particles of sunflower stalks binded together by chitosan, a bio-based binder. The acoustical performance in absorption was found to be poor as the material was highly compacted and with low porosity. The present study focuses on the acoustical properties of a higher porosity composite, with lower density while the mechanical rigidity remains fairly high. A higher absorption coefficient is obtained. The experimental results on the absorption coefficient are compared to the prediction of a model involving 5 physical parameters (porosity, tortuosity, airflow resistivity, thermal and viscous char-acteristic lengths). The characterization methods to determine these parameters are described. The com-parison between experimental and theoretical results shows that this material exhibits peculiar microstructural features. It is found that the sound absorption properties can involve dead-end pores or clusters and multiple porosity scales in the material.
\end{abstract}

\section{Introduction}

In recent years, the development of sustainable economy in modern societies has encouraged research on eco-design and on sustainable building materials. There is a growing interest in the development of new materials capable of contributing in this emerging topic. Mati-Baouche et al. [27], have recently developed a method of manufacturing $100 \%$ natural eco-insulating composite materials based on sunflower stalks particles binded together with a bio-based glue obtained from chitosan [11,28]. Chitosan is a biopolymer of $\beta$-(1,4)-linked 2-acetamido-2-deoxy-Dglucopyranose and 2-amino-2-deoxy-D-glucopyranose obtained by alkaline deacetylation of chitin, the main component of the exoskeleton of crustaceans [29]. Chitosan is the only cationic polysaccharide due to its positive charges $\left(\mathrm{NH}_{3}^{+}\right)$at acidic $\mathrm{pH}(<7)$ [6]. These charges increase retention at the site of application [19]. Chitosan is widely produced worldwide, especially in the east. The bio-based composites made from chitosan and sunflower particles are porous and their properties can be tailored mainly by varying the chitosan content and the compaction pressure used for the composite preparation, which have a direct influence on the density of the produced material. The main application of this study is to propose a new high performance $100 \%$ bio-based material for building engineering.

The new building materials are also required, if possible, to perform several functions simultaneously. They can be expected to satisfy structural, thermal and acoustical demands The study by Mati-Baouche et al. [27] showed that a fairly high compaction pressure is desirable to obtain certain thermal and mechanical performances.

The first studies on the acoustics of sustainable materials were proposed in the seventies and eighties with contributions on the acoustic properties of ground, vegetation, trees, foliage and plant leaves $[4,5,9,25,26]$. Studies on the acoustic properties of building materials containing bio-based particles were later proposed $[36,40]$. Recyclable materials were studied more recently with contributions by Swift et al. [38], Horoshenkov and Swift [20] or Benkreira et al. [7]. An exhaustive review on sustainable materials for acoustic application was recently proposed by Asdrubali et al. [2]. They proposed a classification and a rating of the sustainability of these materials, their environmental impact in terms of global warming or acidification potential and discussed their advantages and disadvantages. They distinguished the natural materials (plants, leaves trees, ground), the recycled materials, and composites materials containing bio based or recycled particles. In building engineering, the acoustic properties of these new materials are not yet fully known or mastered and databases on their 
acoustic properties can be necessary. The use of natural fibers in building engineering can contribute to $\mathrm{CO}_{2}$ reduction through recycling process. However, this raises other issues related to safety (resistance to fire, toxicity). Natural and recycled materials represent a good way to reduce the emission impact. The possibilities offered by bio-based materials for sustainable development and building engineering seem limitless. Recent other studies involving the acoustical properties were proposed by Glé et al. [17], Glé et al. [18], Asdrubali et al. [3] or Chabriac et al. [10]. It should be noted that certain studies deal with special features of bio-based materials. Olny and Boutin [30] as well as Gle et al. [17] have shown the importance of the double porosity effect on the acoustical properties. Lagarrigue et al. [21] have shown that sound diffusers based on natural material such as bamboo rods can behave as sonic crystals and display metamaterial features. Verdière et al. [39] have shown that a parallel transfer matrix approach can be used to describe the acoustic properties of a parallel assembly of hollow cylinders such as straws.

In the present study, we focus on a new specific acoustical feature of bio-based materials related to the possible presence of dead-end pores or cluster in these materials. Sunflower composites with a mass ratio chitosan/sunflower of $4.3 \%$, a mean particle size of shredded sunflower stalks of $6.3 \mathrm{~mm}$ and a density of $150 \mathrm{~kg} / \mathrm{m}^{3}$ were produced. The amount of chitosan and the compaction rate applied led to a material with a thermal conductivity of $0.06 \mathrm{~W} \mathrm{~m}^{-1} \mathrm{~K}^{-1}$ and a maximum stress at break of about $2 \mathrm{MPa}$. The acoustical properties were also studied. The results on the absorption properties were found to be rather poor with an absorption coefficient lower than 0.3 in the frequency range $50-4000 \mathrm{~Hz}$. This study confirmed that high porosity is generally desired to achieve good sound absorption. This feature is fully compatible with light materials requirements but not necessarily with high tensile strength and maximum stress at break or with certain thermal properties. The acoustic absorption in a porous material strongly depends upon several physical parameters among which are the porosity and the airflow resistivity. For low values of porosity and high values of airflow resistivity, the sound absorption can be low and this can explain the poor results obtained. Higher values of absorption can be expected for more porous materials. Depending on the desired performance, the right trade-off between thermal, mechanical and acoustic properties needs to be determined. In the present study, a new sample with higher porosity was studied with a particular attention on its acoustical properties.

The article is organized as follows: In Section 2, the fabrication process of the sunflower composite is recalled. Mechanical and thermal properties are given. Physical parameters necessary for the acoustical description are presented and their measured values are given. The acoustical modelling using these parameters is summarized. In Section 3, the experimental results on the acoustic absorption coefficient and on the transmission loss are presented and discussed. A comparison between the experimental results with the theoretical predictions is proposed and analyzed to explain the discrepancies. It is shown that peculiar features of the microstructure must be taken into consideration.

\section{Material and methods}

\subsection{Recall of the fabrication process of the bio-based composite}

Bio-based composites from shredded stems of sunflower and chitosan were produced as described previously [27] but using conditions leading to samples with higher porosity (Fig. 1). A chitosan solution at $4 \%(\mathrm{w} / \mathrm{v})$ was made in $1 \%(\mathrm{v} / \mathrm{v})$ acetic acid and mixed for 5 min with sunflower stalk particles (mix of bark and pith particles) having particle sizes between 3 and $5 \mathrm{~mm}$. The ratio chitosan/sunflower particles was $0.066 \mathrm{~g} / \mathrm{g}$. The mixture was used to fill a polyvinylchloride (PVC) mold $(180 \mathrm{~mm} \times$ $50 \mathrm{~mm} \times 40 \mathrm{~mm}$ ) and was compacted during $1 \mathrm{~min}$ at $20^{\circ} \mathrm{C}$ under a pressure of $32 \times 10^{-3} \mathrm{MPa}$ using weights. After drying at $50^{\circ} \mathrm{C}$ for $50 \mathrm{~h}$ in an oven, the resulting composites $(180 \mathrm{~mm} \times$ $50 \mathrm{~mm} \times 20 \mathrm{~mm}$ see Fig. 1) were firstly thermally characterized as described previously [27]. They were then cut to obtain slender shapes of $180 \mathrm{~mm} \times 24 \mathrm{~mm} \times 12 \mathrm{~mm}$ to do tensile mechanical characterization (tensile tests) as described previously [27] or cylindrical shape of $44.4 \mathrm{~mm}$ diameter for the purpose of determining the acoustic properties.

\subsection{Mechanical and thermal properties}

Young's modulus ( $E^{\prime}(\mathrm{MPa})$ corresponds to the stiffness of the specimen. The more Young's modulus increases, the more rigid is the material. $\sigma_{\max }(\mathrm{MPa})$ is the maximum stress reached during tensile tests that the sample can sustain before being broken. These two parameters characterize the mechanical strength of the material. The mechanical properties of the bio-based composite chitosan/sunflower stalks particles in tensile mode attained up to $0.14 \mathrm{MPa}$ for $\sigma_{\max } \max$ and $60 \mathrm{MPa}$ for $E^{\prime}$. These results are in agreement with those of Mati-Baouche et al. [27] obtained with similar bio-based composites.

The lower the thermal conductivity $(k)$ of a composite is (less than $0.1 \mathrm{~W} \mathrm{~m}^{-1} \mathrm{~K}^{-1}$ ), the more the thermal insulation is significant. The composite obtained in this study can be considered as thermal insulator because of its thermal conductivity that was measured at $0.077 \mathrm{~W} \mathrm{~m}^{-1} \mathrm{~K}^{-1}$. It showed similar thermal properties compared with composites of Mati-Baouche et al. [27] which had thermal conductivities between 0.056 and $0.058 \mathrm{~W} \mathrm{~m}^{-1} \mathrm{~K}^{-1}$ depending on the manufacturing conditions.

\subsection{Basic properties of the material for the acoustical description}

The process described in the previous section was used to produce the new material studied in this article. For the acoustic modelling in this study, the size of the sample, its density and a set of physical parameters are necessary. It should be noted that this description assumes that only the fluid moves and is deformable. This fluid can be seen as an equivalent fluid in the rigid or limp frame approximations [33]. A more refined modelling (not studied in this article) involving the solid frame elasticity is possible. The physical parameters and their measurement techniques will be described in Section 2.5.

Two samples of bio-based composite $(180 \mathrm{~mm} \times 50 \mathrm{~mm} \times$ $20 \mathrm{~mm}$ ) were cut in a cylindrical shape of $44.4 \mathrm{~mm}$ diameter for the purpose of determining the acoustic properties in an impedance tube (Fig. 2). The samples were cut from the same rectangular block and so their basic properties are the same except for the thickness due to inhomogeneities of the sample surface (Table 1).

\subsection{Method for measuring the acoustical performance}

A $44.4 \mathrm{~mm}$ diameter impedance tube (Fig. 2) allows a plane wave normal incidence excitation between 150 and $4100 \mathrm{~Hz}$. This impedance tube can be used to determine:

- The absorption coefficient in the two microphones setup configuration described by Dalmont [12].

- The transfer matrix and transmission loss (TL) in the transmission configuration with the three microphones and two loads described by Salissou et al. [34]. 


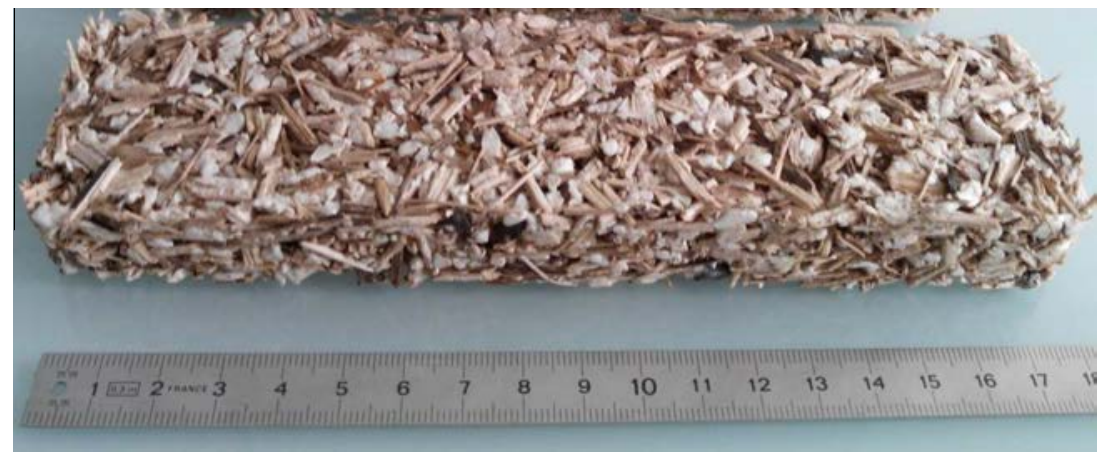

Fig. 1. A sample of sunflower stem/chitosan bio-based composite.

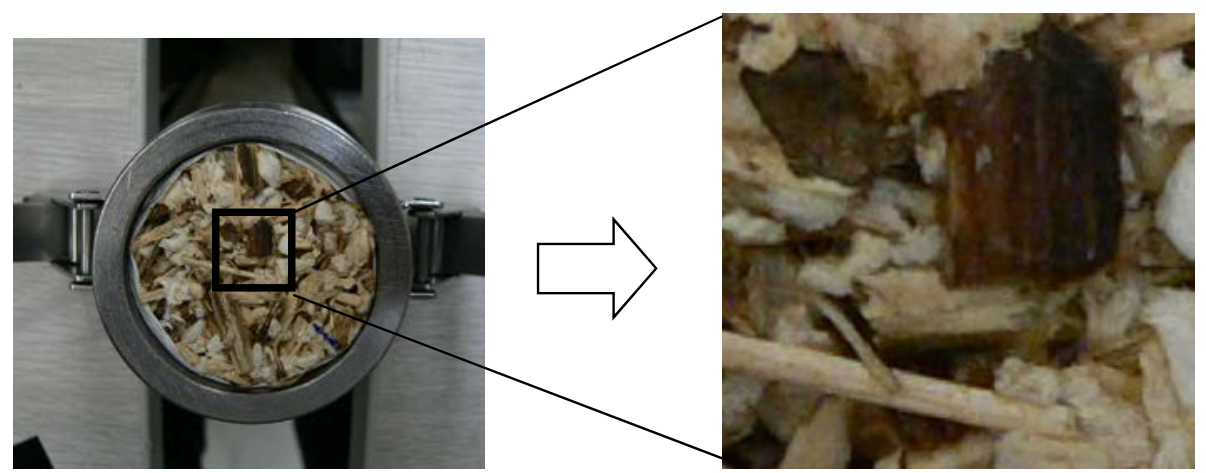

Fig. 2. Sample of sunflower composite of $44.4 \mathrm{~mm}$ diameter inserted in an acoustic impedance tube (44.4 mm diameter Mecanum Inc. impedance tube).

Table 1

Basic properties for the acoustical description.

\begin{tabular}{llll}
\hline & Bulk density $\left(\mathrm{kg} / \mathrm{m}^{3}\right)$ & Diameter $(\mathrm{mm})$ & Thickness $(\mathrm{mm})$ \\
\hline Sample 1 & $186.42 \pm 0.49$ & 44.4 & 18.88 \\
Sample 2 & $186.42 \pm 0.49$ & 44.4 & 19.19 \\
\hline
\end{tabular}

2.5. Physical parameters for the acoustic description and methods for their determination

\subsubsection{Porosities}

In a porous material, the fluid can be contained in inclusions or connected to the surroundings as illustrated in Fig. 3a. The total porosity $\phi_{T}$, a closed porosity $\phi_{C}$ and an open porosity $\phi$ can be defined and are respectively given by the total volume of fluid, the volume of the inclusions or the open volume divided by the total volume of the sample. A simple relationship exists between these porosities:

$\phi_{T}=\phi+\phi_{C}$

The porosity that matters in the propagation of acoustic waves is the open porosity $\phi$, the closed porosity being considered as part of the solid. In addition, as it will be seen, the open porosity will not be sufficient to model accurately the results on the absorption coefficient and on the transmission loss of the bio-based composite. An additional porosity needs to be defined. This parameter is related to the porosity "seen" by an acoustic wave travelling in the porous structure of the material (Fig. 3b). The concept of "kinematic" porosity defined in geophysics can be used. Alternatively, the

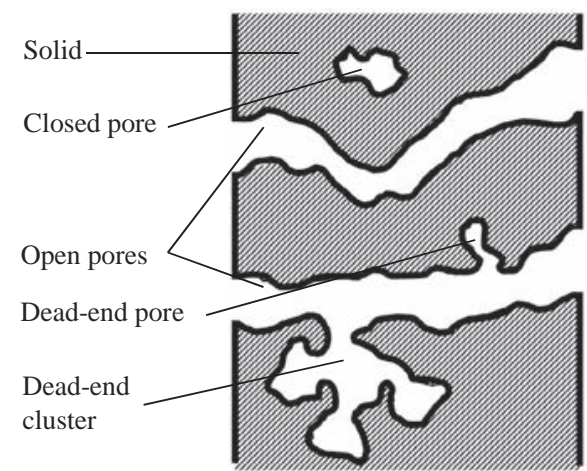

(a)

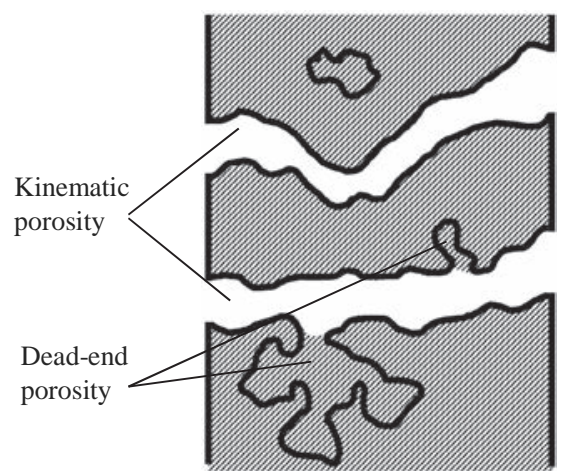

(b)

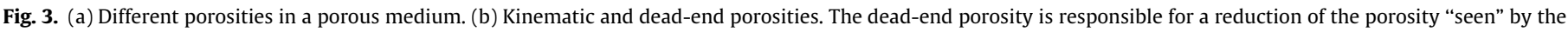
acoustic wave (the kinematic porosity) and to additional resonances in the absorption curve due to the cavities. 
dead-end porosity [14] can be used instead as a simple relationship exists between the open $\phi$, kinematic $\phi_{k}$ and dead-end $\phi_{D E}$ porosities:

$\phi=\phi_{k}+\phi_{D E}$

2.5.1.1. Determination of the open porosity $\phi$. The pressure/mass method proposed by Salissou and Panneton [35] is used. It consists in measuring the mass of a container at different pressure up to 6 bars. The measurements are carried out with and without porous material inside the container. From measurements at different pressures with and without sample in the container, it is possible to infer the total open porosity of the sample. Another method based on comparison of air volumes was proposed by Leclaire et al. [22]. The total porosity was measured by the method by Salissou and Panneton [35] and was found to be $86.6 \pm 1.2 \%$.

2.5.1.2. Determination of the kinematic $\phi_{k}$ and dead-end $\phi_{D E}$ porosities. A simple method was developed by Dupont et al. [15] in order to determine the kinematic porosity from the transmission of ultrasonic waves through a layer of a porous material (Fig. 4). However, this method is difficult to implement for resistive materials for which the transmitted signal is weak.

This method was applied to sample 2 and has provided useful results. Fig. 5 presents the logarithm of the transmission coefficient as a function of the square root of the angular frequency. A linear curve fit provides a straight line. The intercept with the vertical axis at $0 \mathrm{~Hz}$ leads to an estimate of the kinematic porosity seen by the ultrasonic wave. The method requires the value of the tortuosity (described in a subsequent section), which is $\alpha_{\infty}=2.37$.

The kinematic porosity deduced from this method is found to be $\phi_{k}=68 \%$ for sample 2 . Although the results need to be considered with caution, they show that the order of magnitude of the porosity measured is significantly less than the value found in the classical pressure/mass method (86.6\%). Using Eq. (2), the dead-end porosity is found to be $18.6 \%$. The presence of a non negligible dead-end porosity is confirmed by the use of a method developed by Fellah et al. [16]. This method is based on the reflection of ultrasonic waves at the surface of a material at different angles of incidence (Fig. 6). It is thought that this method should also provide an estimate of the kinematic porosity $\phi_{k}$ as it is based on sound wave propagation. The evaluation of the kinematic porosity is thought to represent an originality of this work.

Four angle were tested $\left(20^{\circ}, 30^{\circ}, 40^{\circ}\right.$ and $\left.50^{\circ}\right)$ and from these measurements and a statistical analysis, a value of $\phi_{k}=72 \% \pm 1 \%$ is found for sample 1 , face $A$ and $\phi_{k}=68.5 \% \pm 4 \%$ for sample 2 face A. The method based on ultrasonic reflection is thought to provide less measurement error and is fairly repeatable. Therefore, this method is preferred to the transmission method. The value considered for the kinematic porosity is $\phi_{k}=72 \pm 4 \%$.

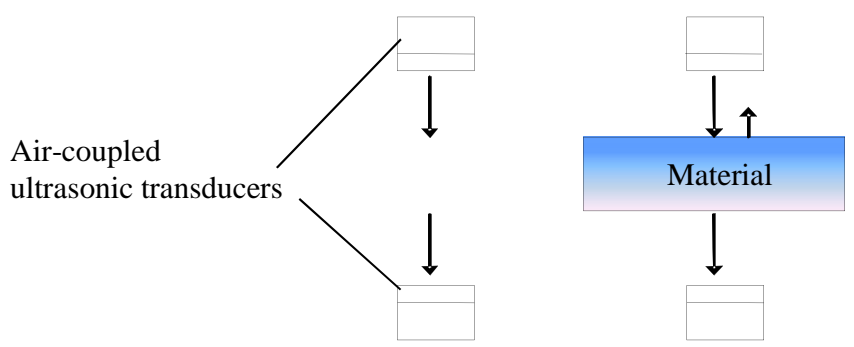

Fig. 4. Principle of the measurement of kinematic porosity from the logarithm of the transmission coefficient $\ln (T)$ [15].

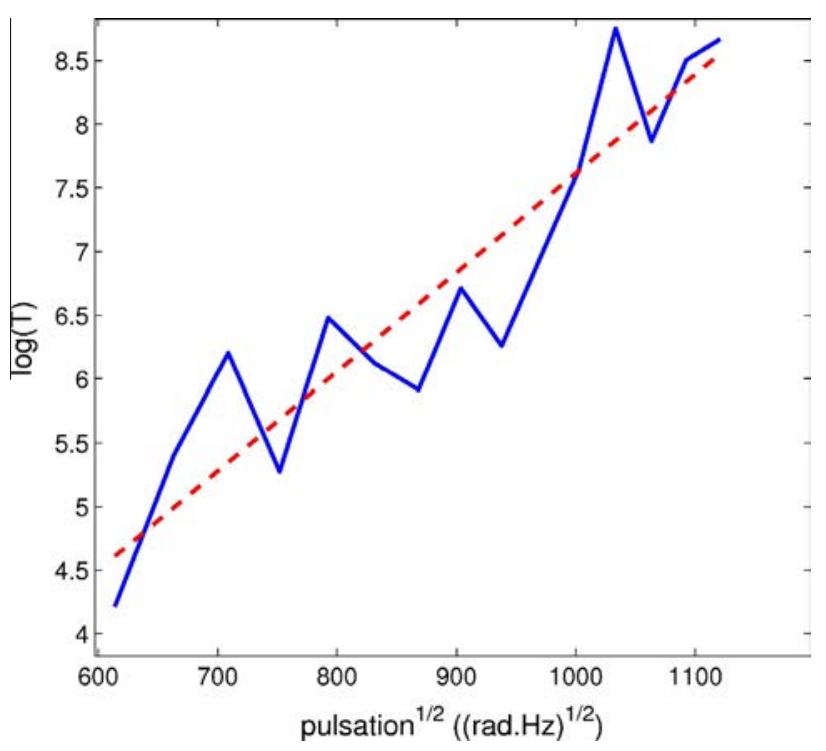

Fig. 5. Logarithm of the transmission coefficient as a function of the square root of the angular frequency for sample 2 . The intercept of the straight line with the vertical axis (at $0 \mathrm{~Hz}$ ) leads to the kinematic porosity.

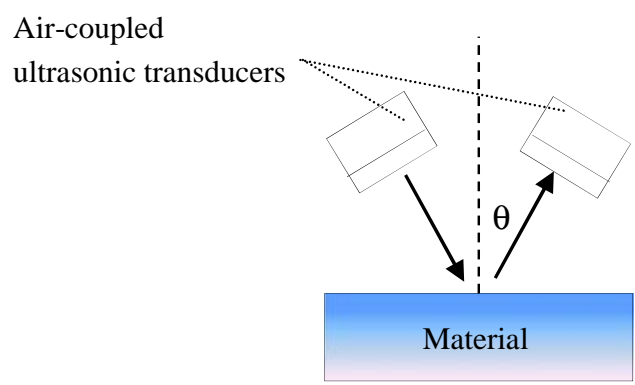

Fig. 6. Principle of the measurement of kinematic porosity and tortuosity from reflected ultrasonic waves. At least two measurements with two different angles are necessary.

\subsubsection{Airflow resistivity}

A classical method using a standard resistivimeter is used (see [8]). The principle is based on the application of a pressure gradient across a layer of material of a given thickness and on the measurement of the resulting flow velocity in the sample. The measured airflow resistivity was $\sigma=49000 \pm 800 \mathrm{Ns} / \mathrm{m}^{4}$.

\subsubsection{Tortuosity}

The tortuosity was also measured from airborne ultrasonic wave transmission through the sample (the same experimental setup is used as in Fig. 4). The method used is a variant of the methods proposed by Leclaire et al. [23], Leclaire et al. [24]. The time signal used for excitation is a periodic pulse train signal containing 10-20 sine periods. This allows to provide more energy for a given ultrasonic frequency so that the signal can propagate through the sample. The times of flight, necessary for the determination of tortuosity were measured using a simple correlation function between the signal without sample between the emitter and the receptor and the signal with sample between them. Two pairs of transducers Ultran NCG50-D25 (central frequency of $50 \mathrm{kHz}$ ), NCG100-D25 (central frequency of $100 \mathrm{kHz}$ ) can be used for the measurements. The method allows to determine the tortuosity $\alpha_{\infty}$ and an equivalent length $L_{e q}$ [23]. This length is a combination of the viscous and thermal characteristic lengths $\Lambda$ and $\Lambda^{\prime}$. 


\subsubsection{Viscous and thermal characteristic lengths}

The viscous characteristic length $\Lambda$ and thermal characteristic length $\Lambda^{\prime}$ cannot be easily determined by a simple method (see [24]). One way of estimating these parameters is to use impedance tube measurements and inverse or indirect methods using transmission data [32,31,13]. For this study, the viscous and thermal characteristic lengths were measured using this method.

2.5.5. Summary of the physical parameters for the acoustical model

The measured physical parameters necessary for the theoretical description of sunflower composites are summarized in Table 2. These parameters play a role in the model described in the next section. In the model, the material thickness was taken to be $19 \mathrm{~mm}$.

\section{Calculation of the sound absorption properties of sunflower/chitosan bio-based composites}

In this section, a summary of the model for the acoustical properties of sunflower composite is presented. This model is based on the modelling of sound propagation in porous media. The purpose of this article is not to go into lengthy details for the acoustic modelling and only a summary of the model is given.

\subsection{Summary of the model}

The complex density and bulk modulus of the effective fluid in the pores depend on the angular frequency $\omega$ and are given by

$$
\begin{aligned}
\rho_{e}(\omega) & =\tau_{\infty} \rho_{0}\left(1-j \frac{\phi}{\omega \rho_{0} \tau_{\infty}} \sigma G(\omega)\right), \quad K_{e}(\omega) \\
& =\frac{\gamma P_{0}}{\gamma-(\gamma-1)\left(1-j \frac{H_{P}}{2 \omega} G_{P}\right)^{-1}}
\end{aligned}
$$

where $G$ and $G_{p}$ are correction function given in the classical Johnson-Champoux-Allard model by (see [1]):

$$
\begin{aligned}
F(\omega) & =\sqrt{1+j 4 \frac{\eta \rho_{f} \tau_{\infty}^{2}}{\sigma^{2} \phi^{2} \Lambda^{2}} \omega,} G(\operatorname{Pr} \omega) \\
& =\sqrt{1+j \frac{\eta \rho_{f} \tau_{\infty}^{2}}{\sigma^{2} \phi^{2} \Lambda^{\prime 2}} \operatorname{Pr} \omega}
\end{aligned}
$$

$$
\begin{aligned}
H & =\frac{\sigma^{2} \phi^{2} \Lambda^{2}}{4 \eta \rho_{0} \tau_{\infty}^{2}}, \quad G(\omega)=\sqrt{1+j \frac{\omega}{H}}, \quad H_{P} \\
& =\frac{16 \eta}{\operatorname{Pr}^{\prime 2} \rho_{0}}, \quad G_{p}(\omega)=\sqrt{1+j \frac{\omega}{H_{P}}}
\end{aligned}
$$

where (see Table 2) $\phi$ is the total open porosity, $\alpha_{\infty}$ is the tortuosity, $\sigma$ is the airflow resistivity, $\Lambda$ and $\Lambda^{\prime}$ the viscous and thermal characteristic lengths, respectively. $j$ is the unit imaginary complex number. $\rho_{0}$ is the density of air, $P_{0}$ the atmospheric pressure, $\eta$ the air dynamic viscosity and $P r$ the Prandtl number.

The complex phase velocity of the acoustic wave is given by

$c_{\varphi}(\omega)=\sqrt{\frac{K_{e}(\omega)}{\rho_{e}(\omega)}}$

The complex wavenumber is given by $k(\omega)=\frac{\omega}{c_{\varphi}(\omega)}$

and the complex characteristic impedance of the equivalent fluid is given by

$Z_{C}(\omega)=\rho_{e}(\omega) c_{\varphi}(\omega)$

\subsection{Multilayers of porous materials}

In order to establish the absorption coefficient and transmission loss of multilayers of porous materials, it is necessary to define a transfer matrix for each layer of the system. The layers are assumed of infinite lateral extent. The multilayer system is decomposed into $\mathrm{N}$ elements [1,37]. The transfer matrix $\left[T_{i}\right]$ of a layer indiced $i$ of thickness $l_{i}$, open porosity $\varphi_{i}$, wavenumber $k_{i}$ and characteristic impedance $Z_{C i}$ is given by

$$
\left(\begin{array}{c}
p_{i} \\
v_{i}
\end{array}\right)=\left[T_{i}\right]\left(\begin{array}{l}
p_{i-1} \\
v_{i-1}
\end{array}\right)=\left(\begin{array}{ll}
\cos \left(k_{i} l_{i}\right) & \frac{j z_{C i}}{\phi_{i}} \sin \left(k_{i} l_{i}\right) \\
\frac{j \phi_{i}}{Z_{G i}} \sin \left(k_{i} l_{i}\right) & \cos \left(k_{i} l_{i}\right)
\end{array}\right)\left(\begin{array}{c}
p_{i-1} \\
v_{i-1}
\end{array}\right)
$$

where $p_{i}$ and $v_{i}$ are the acoustic pressure and particle velocity at the front of the $i$ th layer expressed as functions of the pressure $p_{i-1}$ and velocity $v_{i-1}$ at the back of the layer.

For a multilayered material containing $N$ layers (Fig. 7), the relationship between the last and first layer is

$$
\left(\begin{array}{c}
p_{N} \\
v_{N}
\end{array}\right)=\left[T_{N}\right]\left[T_{N-1}\right] \ldots\left[T_{0}\right]\left(\begin{array}{c}
p_{0} \\
v_{0}
\end{array}\right)
$$

\subsection{Acoustic indicator of the multilayer system}

With the global transfer matrix:

$\left[T_{N}\right]=\left[\begin{array}{ll}t_{11}^{N} & t_{12}^{N} \\ t_{21}^{N} & t_{22}^{N}\end{array}\right]$ by:

The sound transmission coefficient at normal incidence is given

$|\tau|=\left|\frac{2}{t_{11}^{N}+t_{22}^{N}+t_{12}^{N} / Z_{0}+t_{21}^{N} Z_{0}}\right|$,

and the transmission loss by

$T L=-20 \log _{10}(|\tau|)$,

where $Z_{0}$ is the characteristic impedance of air. Then, from the appropriate system transfer matrix, the normal incidence surface impedance of the studied configuration is given by:

\begin{tabular}{|c|c|c|c|c|c|c|}
\hline Total open porosity $\phi(\%)$ & Tortuosity $\alpha_{\infty}$ & Airflow resistivity $\sigma\left(\mathrm{Ns} / \mathrm{m}^{4}\right)$ & $\Lambda(\mu \mathrm{m})$ & $\Lambda^{\prime}(\mu \mathrm{m})$ & Kinematic porosity (\%) & Dead-end porosity (\%) \\
\hline $86.6 \pm 2$ & $2.37 \pm 0.15$ & $41800 \pm 500$ & 11.3 & 150 & $72 \pm 4$ & $14.6 \pm 4$ \\
\hline
\end{tabular}

$Z_{S}=\frac{t_{11}^{N}}{t_{21}^{N}}$

and the normal sound absorption coefficient by:

$\alpha_{N}=1-\left|\frac{Z_{S}-Z_{0}}{Z_{S}+Z_{0}}\right|^{2}$

Table 2

Physical parameters necessary for the acoustical model. 


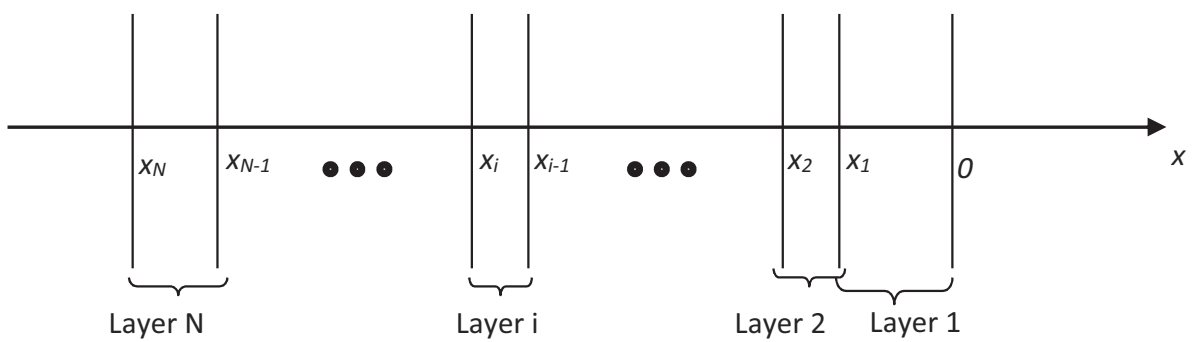

Fig. 7. Representation of a multilayer material in the transfer matrix method (TMM).

\subsection{Layer of porous sunflower composite on a rigid wall}

We consider the practical situation in our study where a layer of sunflower composite is applied on a rigid wall. In this case only one layer is considered. The particle normal velocity at the rigid wall is 0 and the absorption coefficient and TL are given by Eqs. (13) and (15).

\subsection{Layer of porous sunflower composite backed by an air cavity and a rigid wall}

This case corresponds to a bilayer material where the first layer is a cavity of thickness $l_{\text {cav }}$. The transfer matrix for the air cavity is given by

$$
\left[T_{\text {cav }}\right]=\left[\begin{array}{ll}
\cos \left(k_{0} l_{\text {cav }}\right) & j Z_{0} \sin \left(k_{0} l_{\text {cav }}\right) \\
\frac{j}{Z_{0}} \sin \left(k_{0} l_{\text {cav }}\right) & \cos \left(k_{0} l_{\text {cav }}\right)
\end{array}\right]
$$

where $Z_{0}$ is the characteristic impedance of air and $k_{0}$ the wavenumber in air. The particle velocity at the rigid wall is also 0 and the absorption coefficient and TL are given by Eqs. (13) and (15) in the bilayer configuration.

\section{Results and comparison with theoretical predictions}

\subsection{Experimental results}

The acoustical measurements using the impedance tube described in Fig. 2 were carried out under the following conditions: room temperature of $22.9^{\circ} \mathrm{C}$, atmospheric static pressure of $977 \mathrm{hPa}$ and hygrometry of $58 \%$. For each configuration, the sample is positioned in the impedance tube and can be backed by a rigid wall (hard-backed configuration) or by a variable thickness air cavity followed by a rigid wall.

The hard-backed absorption coefficient and the transmission loss were measured on the two samples produced and for two different incidence faces A or B (by turning the sample around). Therefore, four curves are presented. This study allows to observe differences in the experimental results due to inhomogeneities of the sample surface and thickness and also to differences in the thicknesses. The results are presented in Fig. 8.

For the absorption coefficient, the first peak is due to viscothermal interactions in the boundary layer of the fluid near the solid surface in the pores. The second peak corresponds to the first vibrational mode of the sample. This peak depends on the nature of the material, on the lateral boundary conditions (sampleimpedance tube) and also on the boundary conditions at the surfaces of the sample (rigid wall for a hard-back boundary condition).

This interpretation is confirmed by the absorption coefficients measured on the same sample but for different air cavities backing the sample (Fig. 9). Indeed, whatever the thickness of the air cavity, the frequency of the second peak due to the sample vibration remains the same except for the zero cavity case in which the
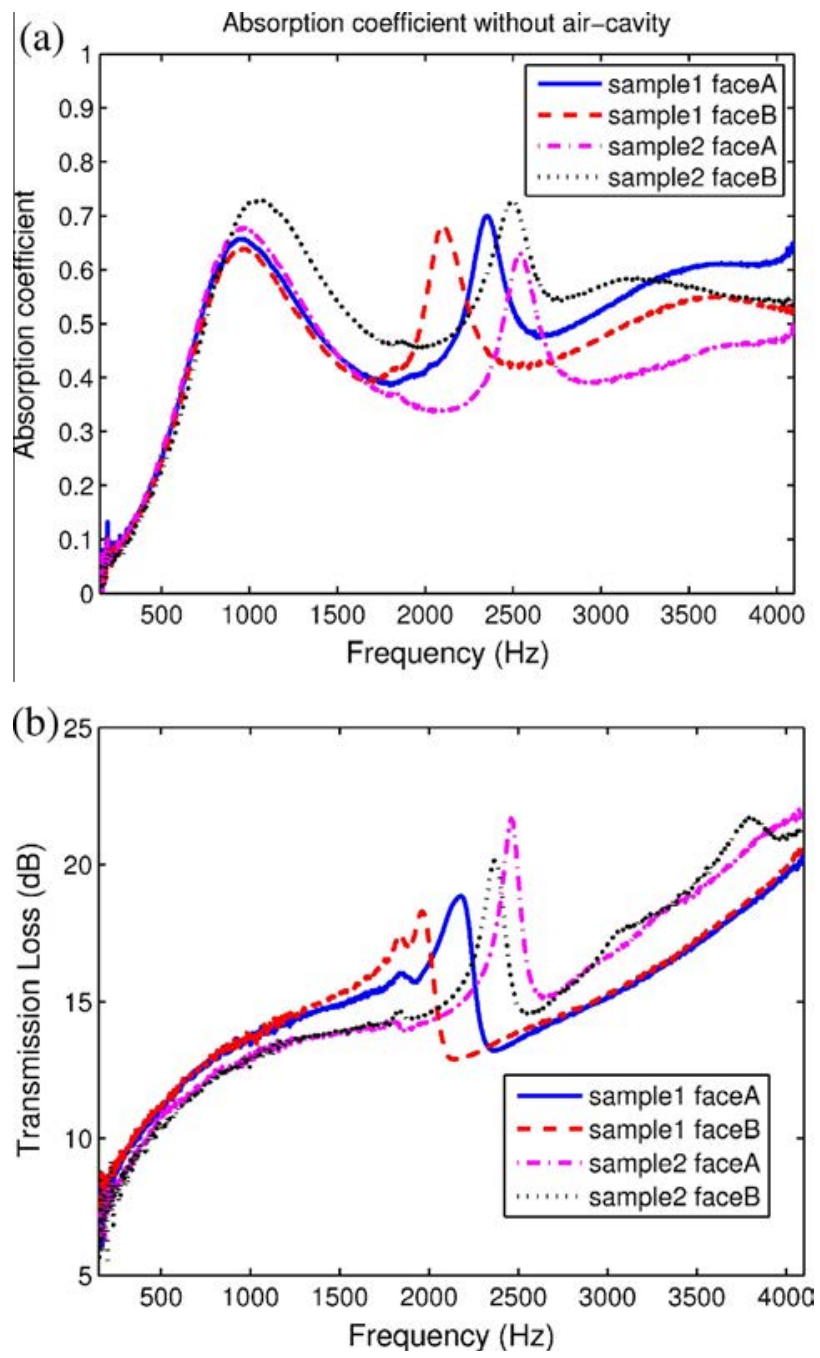

Fig. 8. Acoustic indicators (a) absorption coefficient (hard-back configuration) and (b) Transmission Loss (TL) measured on two samples and tested for 2 incidence faces.

contact between the sample and the hard backing piston modify the boundary condition imposed to the sample. Below the frequency of the vibrational mode (second peak), the material can be assimilated to an equivalent fluid in the "rigid frame" approximation while above the vibration peak, the material can under certain conditions be considered to have a "limp" frame [33].

It is observed that the absorption curves are similar under the vibration peak (except for sample 2 face B). However, the greater variability for the second absorption peak (the vibration mode) results in a greater variability of the absorption peak at higher frequencies. 


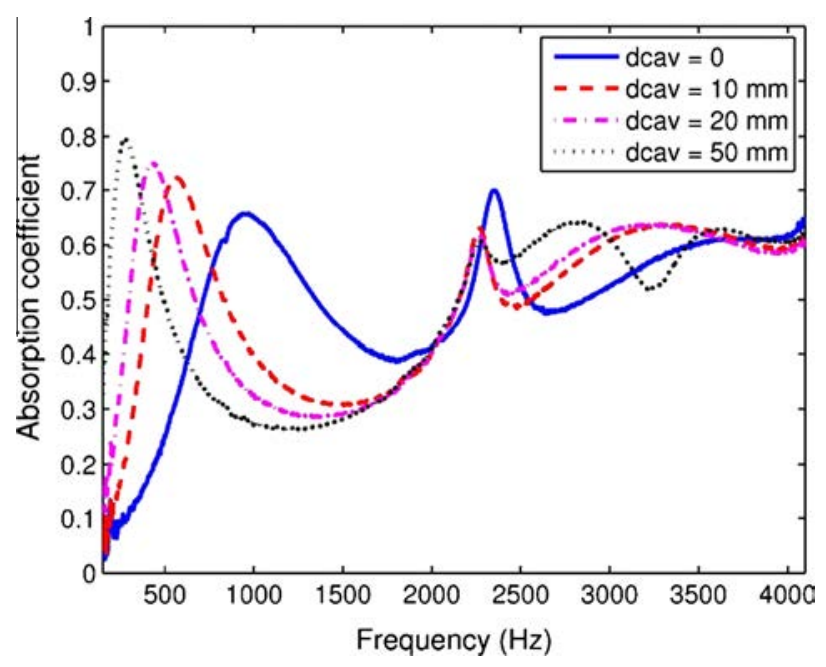

Fig. 9. Absorption coefficients measured on sample 1 for the incidence face A for air cavities backing the sample from 0 (hard back) to $50 \mathrm{~mm}$.

The differences observed on the absorption coefficient for the same sample tested with different entry faces for the waves seem to indicate that the material is not totally homogeneous (at the scale of the wavelengths) along the thickness as well as on the sample surface. The cylindrical samples seem to have insufficient diameters to insure full homogenization of the properties at the wavelengths scales, especially at high frequencies. In addition, glue patches that can be produced in the sample fabrication might reduce further more the homogeneity.

The analysis of the transmission loss results seems to confirm the previous observations. The curves for transmission loss show little discrepancies below the vibration resonance peak. Also, it is observed that the differences between two measurements (faces $A$ and $B$ ) on the same sample are small. The differences observed can also be explained by the differences on the thicknesses of the samples.

The analysis of Fig. 9 shows that air cavity backing the sample can shift the visco-thermal absorption peak to lower frequencies.

Despite the dispersion and variability observed on the acoustic indicators depending on the sample and on the entry face for the waves, it is possible to determine averaged experimental curves for the absorption coefficient and for the transmission loss. This will also provide us with a standard deviation in the comparison with theoretical predictions proposed in the next section.

\subsection{Comparison with the prediction of a model for the sound absorption properties}

The experimental results presented earlier were averaged to obtain a single curve. These results were then compared to the theoretical predictions provided by Eqs. (13) and (15) in which the physical parameters determined earlier were used. Fig. 10 shows the theoretical and experimental results on the absorption coefficient and on the transmission loss. It appears that the model cannot predict very well the experimental results and a fairly high difference is observed between experimental and theoretical results.

\section{Discussion}

It is thought that the high discrepancy observed in Figs. 10 may be explained by peculiarities in the material microstructure. From the observation of the material and the analysis of the acoustic
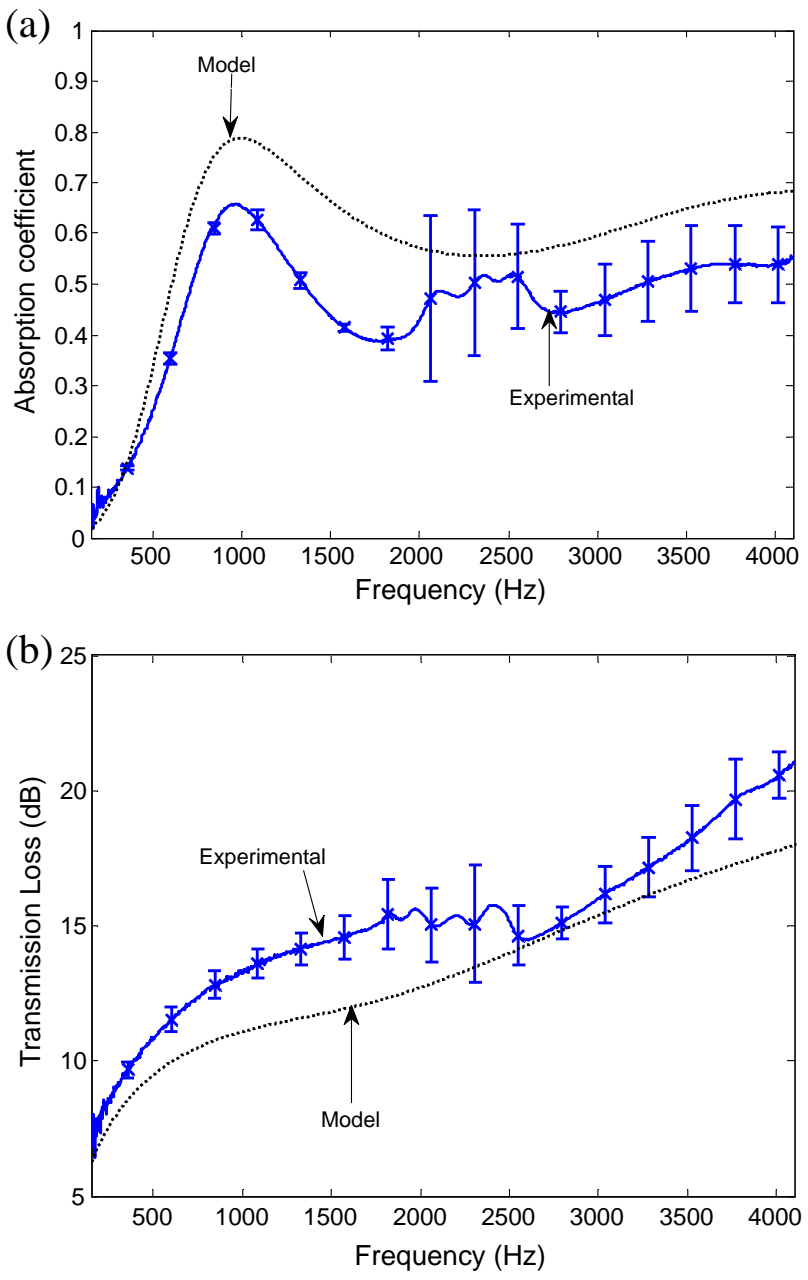

Fig. 10. Comparison between the experimental results and the theoretical predictions for (a) the absorption coefficient and (b) the transmission loss.

indicators, a first interpretation can be proposed: The JohnsonChampoux-Allard (JCA) model is fed with 5 physical parameters, among which is the total open porosity. However, the JCA model cannot account for the presence of dead-end pores in certain materials. A model capable of dealing with dead-end pores was proposed by Dupont et al. [14]. It involves the use of the kinematic porosity in the JCA (or any other) model instead of the total open porosity. Furthermore, the resonance effect due to the presence of lateral cavities or resonators (the dead-end pores) can also be incorporated in the model.

The classical methods for measuring the total open porosity used in the JCA model are based on pressure/mass measurement [35] or on comparison of air volumes [22] while the kinematic porosity was determined by an acoustic method based on the reflection of ultrasonic waves [16].

In order to confirm the influence of dead-end porosity, a correction for the porosity used in the JCA model was made. Instead of $86.6 \%$ (value of the total open porosity), the value of $72 \%$ (kinematic porosity) was used in the JCA model, the difference corresponding to the dead-end porosity (14.6\%). This correction has provided a sensible improvement in the match between experimental results and theoretical predictions as shown in Fig. 11. This result seems to show that a non negligible proportion of dead-end pores or clusters exist in the material and this peculiarity of the microstructure has a strong effect of the acoustic indicators. The kinematic porosity was determined by acoustic ultrasonic methods. The fact that an important difference was found between 

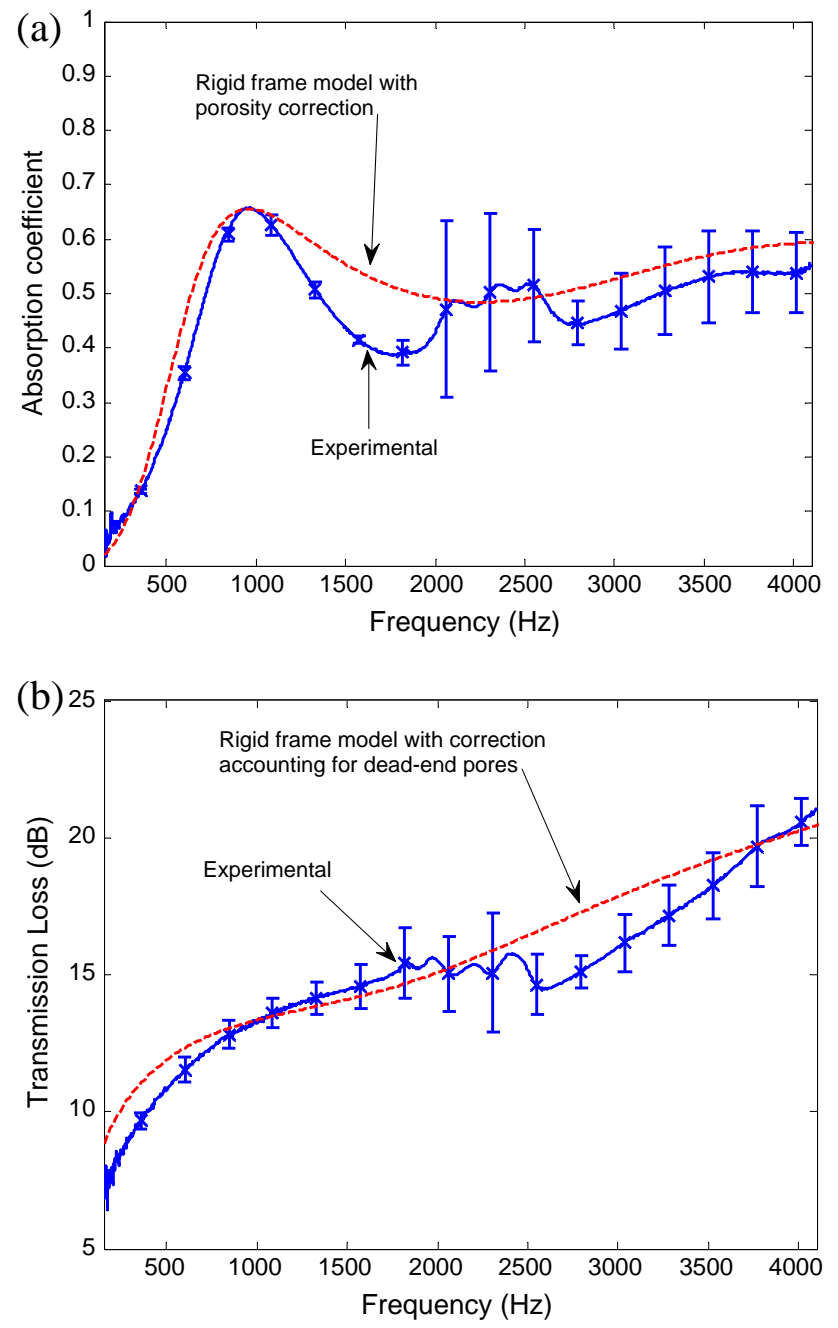

Fig. 11. Comparison between the experimental results and the theoretical predictions for (a) the absorption coefficient and (b) the transmission loss after correction accounting for dead-end porosity.

the porosities measured by classical methods and by acoustic methods is also a confirmation of the presence of dead-end pores or clusters.

The existence of double scale porosities $[30,17]$ could also play a role in the acoustic indicators. The classical methods will determine the total open porosity including the microporosity of the pith while the acoustic waves are thought to be more sensitive to the macroporosity created by the shredded sunflower particles (bark and pith) in the fabrication process.

With a simple porosity correction, the match between theory and experiments is much better and within experimental error in most parts of the curves. For this reason, the resonance effect due to the presence of dead-ends or the double porosity effect was not studied in the present contribution. These effects could be investigated in future works.

\section{Conclusion}

A 100\% bio-based material made from shredded sunflower stem particles (bark and pith) binded together with a chitosan binder was produced. The porosity of the material was higher than earlier samples in order to improve the acoustical performance while keeping a reasonably high tensile strength and maximum stress at break. The thermal conductivity was also kept fairly low for thermal insulation. The acoustic absorption of this material reached a peak of 0.7 .

Classical material characterization techniques were presented and used to determine the physical parameters necessary for the theoretical description of the material.

A classical model of the acoustics of porous media and on the transfer matrix method was used in the rigid or limp frame approximation. Experiments were also carried out and provided a set of results that were averaged. The comparison between theoretical and experimental results on the acoustic indicators (absorption coefficient and transmission loss) showed that the material seems to contain dead-end pores or clusters and that the kinematic porosity of the material must be considered instead of the total open porosity.

This observation was confirmed by the measurement of porosity by an acoustic method using ultrasonic waves which provided results very different from those obtained by classical methods. The evaluation of the kinematic porosity for the first time in a sustainable material with a technique using reflected ultrasonic waves represents an originality of this work. It confirmed the presence of dead-end pores or clusters in the material.

\section{Acknowledgements}

We are grateful to Professor R. Panneton and Mecanum Inc. (Sherbrooke, Canada) for useful discussions and for lending the $44.4 \mathrm{~mm}$ diameter impedance tube measurement system. We also wish to thank Dr. K. Verdière for useful discussions on the acoustic properties of bio-based materials.

This work was supported by the French National Research Agency (ANR-DEMETHER-10-ECOT-004 grant), Céréales Vallée and Viaméca.

\section{References}

[1] Allard JF, Atalla N. Propagation of sound in porous media: modelling sound absorbing materials. second ed. Southern Gate (Chichester, West Sussex, United Kingdom): Wiley and Sons, Ltd; 2009.

[2] Asdrubali F, Schiavoni S, Horoshenkov KV. A review of sustainable materials for acoustic applications. Build Acoust 2012;19:283-312.

[3] Asdrubali F, Bianchi F, Cotana F, D’Alessandro F, Pertosa M, Pisello AL, et al. Experimental thermo-acoustic characterization of innovative common reed bio-based panels for building envelope. Build Environ 2016;102:217-22.

[4] Aylor D. Noise reduction by vegetation and ground. J Acoust Soc Am 1972;51:197-205.

[5] Aylor D. Sound transmission through vegetation in relation to leaf area, density, leaf width, and breadth of canopy. J Acoust Soc Am 1972:51:411-4.

[6] Barbosa MA, Granja PL, Barrias CC, Amaral IF. Polysaccharides as scaffolds for bone regeneration. ITBM-RBM 2005;26:212-7.

[7] Benkreira H, Khan A, Horoshenkov KV. Sustainable acoustic and thermal insulation materials from elastomeric waste residues. Chem Eng Sci 2011;66 (18):4157-71.

[8] Brouard B, Castagnède B, Henry M, Lafarge D, Sahraoui S. Mesure des propriétés acoustiques des matériaux poreux. Techniques de l'Ingénieur, R6 120 ; 2003. 24 pp. [Measurement of the acoustical properties of porous materials].

[9] Burns S. The absorption of sound by pine trees. J Acoust Soc Am 1979;65:658-61.

[10] Chabriac PA, Gourdon E, Glé P, Fabbri A, Lenormand H. Agricultural byproducts for building insulation: acoustical characterization and modeling to predict micro-structural parameters. Constr Build Mater 2016;112:158-67.

[11] Croisier F, Jérôme C. Chitosan-based biomaterials for tissue engineering. Eur Polym J 2013;49:780-92.

[12] Dalmont JP. Acoustic impedance measurement Part I: A review. J Sound Vib 2001;243(3):427-39.

[13] Doutres O, Salissou Y, Atalla N, Panneton R. Evaluation of the acoustic and nonacoustic properties of sound absorbing materials using a three-microphone impedance tube. Appl Acoust 2010;71:506-9.

[14] Dupont T, Leclaire P, Sicot O, Gong XL, Panneton R. Acoustic properties of airsaturated porous materials containing dead-end porosity". J Appl Phys 2011;110:094903.

[15] Dupont T, Leclaire P, Panneton R. Acoustic methods for measuring the porosities of porous materials incorporating dead-end pores. J Acoust Soc Am 2013;133:2136-45. 
[16] Fellah ZEA, Berger S, Lauriks W, Depollier C, Aristegui C, Chapelon JY. Measuring the porosity and the tortuosity of porous materials via reflected waves. J Acoust Soc Am 2003;113:2424-33.

[17] Glé P, Gourdon E, Arnaud L. Acoustical properties of materials made of vegetable particles with several scales of porosity. Appl Acoust 2011;72:249-59.

[18] Glé P, Gourdon E, Arnaud L. Modelling of the acoustical properties of hemp particles. Constr Build Mater 2012;37:801-11.

[19] He P, Davis SS, Illum L. In vitro evaluation of mucoadhesive properties of chitosan microspheres. Int J Pharm 1998;166:75-88.

[20] Horoshenkov KV, Swift MJ. The effect of consolidation on the acoustic properties of loose rubber granulates. Appl Acoust 2001;62:665-90.

[21] Lagarrigue C, Groby JP, Tournat V. Sustainable sonic crystal made of resonating bamboo rods. J Acoust Soc Am 2013;133:793-802.

[22] Leclaire P, Umnova O, Horoshenkov KV, Maillet L. Porosity measurement by comparison of air volumes. Rev Sci Instrum 2003;74:1366-70.

[23] Leclaire P, Kelders L, Lauriks W, Glorieux C, Thoen J. Determination of the viscous characteristic length in air-filled porous materials by ultrasonic attenuation measurements. J Acoust Soc Am 1996;99:1944-8.

[24] Leclaire P, Kelders L, Lauriks W, Melon M, Brown N, Castagnède B. Determination of the viscous and thermal characteristic lengths of plastic foams by ultrasonic measurements in helium and air. J Appl Phys 1996;80:2009-12.

[25] Martens M. Foliage as low pass filter: experiments with model forests in an anechoic chamber. J Acoust Soc Am 1980;67:66-72.

[26] Martens M, Michielsen A. Absorption of acoustic energy by plant leaves. Acoust Soc Am 1981;69:303-6.

[27] Mati-Baouche N, De Baynast H, Lebert A, Sun S, Sacristan CJ, Leclaire P, et al. Mechanical, thermal and acoustical characterizations of an insulating biobased composite made from sunflower stalks particles and chitosan. Ind Crops Prod 2014;58:244-50.
[28] Mati-Baouche N, Elchinger PH, De-Baynast H, Pierre G, Delattre C, Michaud P. Chitosan as an adhesive. Eur Polym J 2014;60:198-212.

[29] Muzzarelli R. Chitosan. In: Muzzarelli R, editor. Natural chelating polymers. Oxford (UK): Pergamon Press; 1973.

[30] Olny X, Boutin C. Acoustic wave propagation in double porosity media. J Acoust Soc Am 2003;114:73-89.

[31] Olny X, Panneton R. Acoustical determination of the parameters governing thermal dissipation in porous media. J Acoust Soc Am 2008;123:814-24.

[32] Panneton R, Olny X. Acoustical determination of the parameters governing viscous dissipation in porous media. J Acoust Soc Am 2006;119:2027-40.

[33] Panneton R. Comments on the limp frame equivalent fluid model for porous media. J Acoust Soc Am 2007:122:EL217-22.

[34] Salissou Y, Doutres O, Panneton R. Complement to standard method for measuring normal incidence with three microphones. J Acoust Soc Am 2012;131:EL216-22.

[35] Salissou Y, Panneton R. Pressure/mass method to measure the open porosity of porous solids. J Appl Phys 2007;101:7 124913.

[36] Sampathrajan A, Vijayaraghavan N, Swaminathan K. Acoustic aspects of farm residue-based particle boards. Bioresour Technol 1991;35:67-71.

[37] Song BH, Bolton JS. A transfer-matrix approach for estimating the characteristic impedance and wave numbers of limp and rigid porous materials. J Acoust Soc Am 2000;107:1131-52.

[38] Swift MJ, Bris P, Horoshenkov K. Acoustic absorption in re-cycled rubber granulate. Appl Acoust 1999;57:203-12.

[39] Verdière K, Panneton R, Elkoun S. Prediction of the acoustic behavior of a parallel assembly of hollow cylinders. Appl Acoust 2016;102:100-7.

[40] Wassiliev C. Sound absorption of wood-based materials. Appl Acoust 1996;48:339-56. 